\title{
Chromosomal polymorphism and patterns of viability in natural populations of Drosophila melanogaster from cellar and vineyard
}

\author{
A. TABERNER \& A. GONZÁLEZ \\ Departamento de Genética, Facultad de Ciencias Biológicas, Universidad de Valencia, Or. Moliner 50 Burjassot-46100, \\ Valencia, Spain, If 3864379
}

\begin{abstract}
Two neighbouring natural populations of Drosophila melanogaster have been analysed, one from a cellar habitat and the other from a vineyard outside. An extensive study of inversion polymorphism in the two populations has been carried out. Furthermore, the relationship between inversion polymorphism and the viability of the second chromosome has been studied. The data regarding the total frequency of inversion-carrying chromosomes indicate a lower frequency in the cellar population than in the vineyard population. Some possibilities that could explain the behaviour of the chromosomes from the cellar in relation to the peculiar environment of this habitat are discussed. New endemic inversions have been detected in both populations. With respect to the fitness component studied, no differences seem to exist between the cellar and vineyard populations. The frequencies of lethal-carrying chromosomes were the same in the two populations (0.267). There were no significant differences between the distribution patterns of the two populations for homozygote or for heterozygote viabilities. Data on allelism rates of lethals and population sizes help us to characterize certain aspects of both populations.
\end{abstract}

Keywords: cellar, chromosomal polymorphism, Drosophila melanogaster, inversion, viability.

\section{Introduction}

Drosophila melanogaster is a chromosomally polymorphic species, as has been shown in various natural populations by many workers (Mukai \& Yamaguchi, 1974; Mettler et al., 1977; Zacharopoulou \& Pelecanos, 1980; Knibb et al., 1981; Inoue et al., 1984; Rim et al., 1986).

Some studies in this species suggest that the presence or absence of chromosomal inversions might be involved in the adaptability of populations to a given environment (Knibb et al., 1981). Inoue et al. (1984) cited environmental pollution as a possible cause of reduced inversion frequencies. However, there have been few studies on inversion polymorphism in natural populations from specific ecological habitats.

Cellars constitute a peculiar environment for Drosophila. The factors from this habitat are diverse and complex (a high concentration of alcohol, especially ethanol, a greater uniformity of temperature and humidity through the year, limited space, scarcity of light, etc.). Drosophila melanogaster, which is the most abundant Drosophila species in this habitat (Monclús
\& Prevosti, 1978-1979), must have become adapted to all these factors.

This study attempts to characterize the genetic variability of a cellar population of Drosophila melanogaster and a population from outside the cellar (vineyard), by relating the inversion polymorphism to the fitness of second chromosomes estimated by their viabilities. A previous study of two similar populations (cellar and vineyard), situated $30 \mathrm{~km}$ from the populations studied here (González \& Ménsua, 1987a,b), showed that while the total inversion frequency was lower in the cellar population than in the vineyard population, no differences seen to exist with respect to the fitness component studied (viability of the third chromosome).

\section{Materials and methods}

Samples of Drosophila melanogaster were taken from two different habitats in Valencia (Spain): a cellar and an outside location (vineyard) about $2 \mathrm{~km}$ from the cellar. 


\section{Detecion of inversions}

The captures were made in spring simultaneously for both populations. Wild caught males were individually crossed with virgin Oregon $\mathrm{R}$ females, who have the standard-arrangement chromosomes. From each culture, one hybrid larva was examined cytologically for inversions. The total number of $\mathrm{X}$ chromosomes analysed is approximately half the number of autosomes.

For the preparation of the salivary-gland chromosomes, third instar larvae were dissected directly in lactic-acetic orcein and stained for $45 \mathrm{~min}$. Then, the usual squashing technique was used. The nomenclature of already-known inversions was that of Lindsley \& Grell (1972). The inversion breakpoints were established by comparing photographs with photographic representations of Bridges' standard maps (1935).

\section{Extraction and maintenance of second chromosomes}

New samples of Drosophila melanogaster were taken from the two populations studied. The captures were made in spring for the cellar and in winter for the vineyard. Each wild caught male, or one single son from each wild isofemale line, was crossed with virgin females of the Cy/Sp [SM5 $\left.\mathrm{al}^{2} \mathrm{Cy} \mathrm{lt}^{v} \mathrm{cn}^{2} \mathrm{sp}^{2} / \mathrm{Sp}\right\}$ strain (the $\mathrm{X}, \mathrm{II}, \mathrm{IV}$ chromosomes and the cytoplasm of $\mathrm{Cy}$ ) Sp flies had been previously substituted with chromosomes and cytoplasm from the cellar population). A single Cy male from each cross was mated again with three $\mathrm{Cy} / \mathrm{Sp}$ virgin females in the next generation. Finally, in each $\mathrm{F}_{2}$ generation $\mathrm{Cy} /+_{i}$ males $(i=$ no. of line) were crossed with virgin $\mathrm{Cy} /+{ }_{i}$ females to maintain the chromosomes as lines.

\section{Estimation of relative viability}

Homozygote and heterozygote relative viabilities were estimated as follow: crosses were made between $4 \mathrm{Cy}$ / $t_{i}$ females and $4 \mathrm{Cy} /+_{i}$ males with two simultaneous replications in each chromosome line, where ' $i$ ' indicates line number. In the offspring, $\mathrm{Cy} /+_{i}$ and $+_{i} /+_{i}$ flies segregate in an expected ratio $2: 1$. The relative viabilities of random heterozygotes were estimated in a way similar to above by combining two successively numbered lines, i.e., $\mathrm{Cy} /+_{i} \times \mathrm{Cy} /+_{i+1}$ in order to secure a random combination of different chromosome lines. The last line was crossed to the first line. As in the case of homozygotes, four-pair matings were conducted with two simultaneous replications. In both cases, four days after the crosses were made, all eight flies in a vial were transferred to a second vial. Four days after the transfer, all flies were discarded. In both the original and the transferred vials, all flies counted until the 18th day after the cross or transfer was made. The flies from a cross and its corresponding transfer were considered as a single observation. Relative viability was expressed as the ratio of (the number of wild type progeny flies) to (the number of $\mathrm{Cy}$ progeny flies $+1)$ (cf. Haldane, 1956).

The crosses were made at different times. Each sample dataset was formed by a number of chromosome lines that were chosen at random at the same time. Each of the two populations were analysed at different times. (For the cellar, two samples of 17 lines, one sample of 18 lines and one sample of 8 lines were studied. For the vineyard, two samples of 10 lines, one sample of 21 lines and one sample of 19 lines were studied.)

Homozygote and heterozygote relative viabilities were estimated at the same time within each sample. Before the analyses were performed, all relative viabilities were standardized by sample to the average heterozygote viability of that sample.

\section{Detection of inversions of second chromosome}

Cytological examination of salivary gland chromosomes was performed for each chromosome line. From the homozygote viability experiment, $+_{i} / t_{i}$ males were taken and crossed with virgin Oregon $R$ females. Third instar larvae were used for the inversion analyses as described in the 'Detection of Inversions' section above.

\section{Results}

A study on inversion polymorphism of the two populations was carried out. Secondly, the relationship between the inversion polymorphism and the viability of the second chromosome was studied.

\section{Inversion polymorphism}

Two hundred and ninety-one sets of autosomes from the cellar and 298 from the vineyard were examined cytologically for inversions. The inversions found in the two populations were classified according to the categories adopted by Inoue \& Watanabe (1979), which are modifications of those of Mettler et al. (1977).

The total frequencies of the inversion-carrying chromosomes in the two populations studied are given in Table 1. A lower frequency of inversion-bearing chromosomes was found in the cellar than in the vineyard population for both second $(t=4.145$ d.f. $=\infty$ $P<0.001)$ and third chromosomes $(t=2.939$ d.f. $=\infty$ $P<0.01)$. 
Table 1 Total inversion frequencies of the second and third chromosomes in cellar and vineyard populations

\begin{tabular}{|c|c|c|c|c|}
\hline \multirow{2}{*}{$\begin{array}{l}\text { Population } \\
\text { Chromosome }\end{array}$} & \multicolumn{2}{|c|}{ Cellar } & \multicolumn{2}{|c|}{ Vineyard } \\
\hline & II & III & II & III \\
\hline $\begin{array}{l}\text { No. chromosomes } \\
\text { analysed }\end{array}$ & 291 & 291 & 298 & 298 \\
\hline $\begin{array}{l}\text { No. inversion- } \\
\text { carrying } \\
\text { chromosomes }\end{array}$ & 46 & 82 & 89 & 118 \\
\hline $\begin{array}{l}\text { Total inversion } \\
\text { frequency }(\%)\end{array}$ & \multicolumn{4}{|c|}{$\begin{array}{l}(46 / 291)\langle 82 / 291)(89 / 298)(118 / 298) \\
158+2128.26300+26396+28\end{array}$} \\
\hline
\end{tabular}

The data also indicated that the frequencies of inversion chromosomes were higher for the third than for the second chromosome in both populations $\langle t=3.635$ d.f. $=\infty P<0.001$ in the cellar and $t=2.436$ d. $f_{t}=\infty$ $P<0.05$ in the vineyard).

A total of 11 different inversions were found in the populations studied (Table 2). All the inversions found were paracentric. No inversions were detected in the $\mathrm{X}$ chromosome. The most frequent inversions in both populations were: $\operatorname{In}(3 L) t, \operatorname{In}(3 L) P$ and $\operatorname{In}(3 R) C$. Only the frequencies of both $\ln (2 \mathrm{~L}) t$ and $\ln (3 \mathrm{~L}) \mathrm{P}$ were significantly different in the two populations $(t=5.575$ d.f. $=\infty P<0.001$ for $\operatorname{In}(2 \mathrm{~L}) \mathrm{t}$ and $t=2.295$ d.f. $=\infty$ $P<0.05$ for $\operatorname{In}(3 \mathrm{~L}) \mathrm{P})$.

It is worth noticing that $\operatorname{In}(3 \mathrm{R}) \mathrm{C}$ (the most frequent inversion in the cellar population \} appears as rare cosmopolitan in most reported studies, while in our populations, this inversion has been found with a very high frequency.

Figure 1 shows the 4 new inversions found. $\operatorname{In}(2 \mathrm{~L}) \mathrm{BoI}, \operatorname{In}(2 \mathrm{~L}) \mathrm{VI}$ and $\operatorname{In}(3 \mathrm{R}) \mathrm{BollI}$ had not been described previously. Each was detected in a single individual from one population. However, In $(3 R) B o I$, found in the vineyard population, was previously detected in a cellar population situated $30 \mathrm{~km}$ from ours (González \& Ménsua, 1987a,b). That is the reason why it has been classified as a recurrent endemic inversion.

An interesting point is whether the association of certain inversions in different conditions (Inv-Inv, Inv-St, St-Inv, St-St) is random or not. Since we have data only on the inversion combinations in $F_{1}$-larva from crosses of wild males with Oregon R females, our analysis has to be restricted to the distribution among the offspring larvae. As some of the inversions are very rare, only the three most frequent inversions are use ful for an analysis. The observed numbers of associations between the inversions $\operatorname{In}(2 \mathrm{~L}) \mathrm{t}, \operatorname{In}(3 \mathrm{~L}) \mathrm{P}$ and $\operatorname{In}(3 \mathrm{R}) \mathrm{C}$ and their corresponding standard regions ( $\mathrm{St}$ )

Table 2 Frequencies, by chromosome arm, of the different arrangements of the second and third chromosomes in cellar and vineyard populations

\begin{tabular}{|c|c|c|c|c|c|c|}
\hline Arm & Arrangement & & $\begin{array}{l}\text { Cellar } \\
N=291\end{array}$ & $\begin{array}{l}\text { Freq. } \\
(\%)\end{array}$ & $\begin{array}{l}\text { Vineyard } \\
N=298\end{array}$ & $\begin{array}{l}\text { Freq. } \\
\langle \%\rangle\end{array}$ \\
\hline \multirow[t]{4}{*}{$2 \mathrm{~L}$} & 2L(STANDARD) & & 266 & 91.4 & 229 & 76.8 \\
\hline & $\operatorname{In}(2 \mathbf{L}) \mathbf{t}^{1}$ & $22 \mathrm{D}-34 \mathrm{~A}$ & 24 & 8.2 & 68 & 22.8 \\
\hline & $\operatorname{In}(2 \mathrm{~L}) \mathrm{BoI}^{4}$ & $24 \mathrm{D} / \mathrm{E}-27 \mathrm{C} / \mathrm{D}$ & 1 & 0.3 & 0 & 0.0 \\
\hline & $\operatorname{In}(2 \mathrm{~L}) \mathrm{VI}^{4}$ & $21 \mathrm{~F}-26 \mathrm{~B} / \mathrm{C}$ & 0 & 0.0 & 1 & 0.3 \\
\hline \multirow[t]{2}{*}{$2 \mathbf{R}$} & 2R(STANDARD) & & 270 & 92.8 & 270 & 90.6 \\
\hline & $\ln (2 \mathrm{R}) \mathrm{NS}^{\mathrm{t}}$ & $52 \mathrm{~A}-56 \mathrm{~F}$ & 21 & 7.2 & 28 & 9.4 \\
\hline \multirow[t]{3}{*}{$3 \mathrm{~L}$} & 3L(STANDARD) & & 267 & 91.4 & 255 & 85.6 \\
\hline & $\operatorname{In}\langle 3 \mathrm{~L}) \mathrm{P}^{1}$ & $63 C-72 E$ & 24 & 8.2 & 42 & 14.1 \\
\hline & $\ln (3 \mathrm{~L}) \mathrm{M}^{2}$ & $66 \mathrm{D}-71 \mathrm{D}$ & 0 & 0.0 & 1 & 0.3 \\
\hline \multirow[t]{6}{*}{$3 \mathbf{R}$} & 3R(STANDARD) & & 227 & 78.0 & 217 & 72.8 \\
\hline & $\operatorname{In}(3 R) P^{1}$ & $89 \mathrm{C}-96 \mathrm{~A}$ & 20 & 6.9 & 21 & 7.0 \\
\hline & $\operatorname{In}(3 R) C^{2}$ & $92 \mathrm{D}-100 \mathrm{~F}$ & 42 & 14.4 & 59 & 19.8 \\
\hline & $\operatorname{In}(3 \mathrm{R}) \mathrm{Mo}^{2}$ & $93 \mathrm{D}-98 \mathrm{~F}$ & 1 & 0.3 & 0 & 0.0 \\
\hline & $\operatorname{In}(3 R)$ BollI $^{4}$ & $96 \mathrm{C} / \mathrm{D}-99 \mathrm{C} / \mathrm{D}$ & 1 & 0.3 & 0 & 0.0 \\
\hline & $\operatorname{In}(3 \mathrm{R}) \mathrm{BoI}^{3}$ & $86 E-92 F$ & 0 & 0.0 & 1 & 0.3 \\
\hline
\end{tabular}

$N=$ number of chromosomes analysed; $1=$ common cosmopolitan inversion; 2 = rare cosmopolitan inversion; $3=$ recurrent endemic inversion; $4=$ unique endemic inversion. 

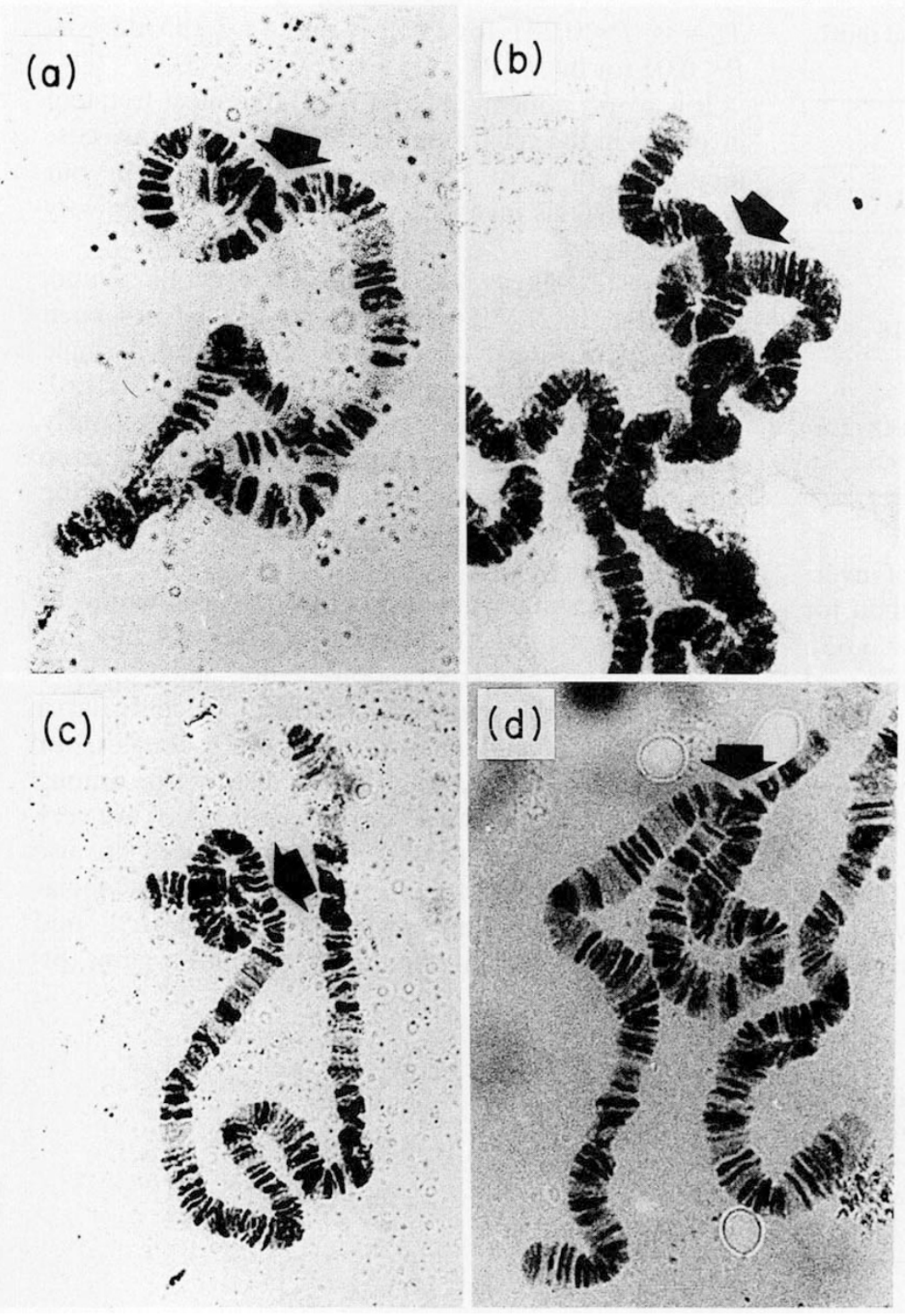

Fig. 1 New inversions found in the populations studied. (A) In(2L) VI (21 F-26B/C); (B) In (2L) Bol (24D $/ \mathrm{E}-$ $27 \mathrm{C} / \mathrm{D}) ;(\mathrm{C}) \operatorname{In}(3 \mathrm{R}) \mathrm{BoIII}(96 \mathrm{C} / \mathrm{D}-99 \mathrm{C} /$ D); (D) ln(3R) Bol (86E-92F).

are given in Table 3. In the cellar population, this test showed that there is only a significant deviation from expectation in the combination $\operatorname{In}(2 \mathrm{~L}) \mathrm{t}$ with $\operatorname{In}(3 \mathrm{~L}) \mathrm{P}$ $\left\langle x^{2}=4.227 \mathrm{~d} . \mathrm{f}=1 \quad P<0.05\right)$, while in the vineyard population, only the combination between $\operatorname{In}(2 \mathrm{~L}) \mathrm{t}$ with In(3R)C showed a significant difference from expectation $\left(\chi^{2}=5.942\right.$ d.f. $\left.=1 P<0.05\right)$.

On the other hand, with respect to the two arms of an autosome, our $F_{1}$ data reflect the natural situation, since only wild males were used for the investigation. Thus, any observed combination (Inv-Inv, Inv-St, $\mathrm{St}-\mathrm{Inv}, \mathrm{St}-\mathrm{St}$ ) in a larva corresponds to the same combination in the chromosome in nature. As shown in Table 4, there is no significant deviation from expectation in either second or third chromosomes in the two populations studied.

\section{Relationship between inversion polymorphism and} viability of the second chromosome

Sixty second chromosomes were extracted from the cellar and 60 from the vineyard. Each one was analysed cytologically and their homozygote and heterozygote relative viabilities were examined.

Inversion frequencies of the second chromosome. The total frequencies of the inversion-carrying chromosomes were: $15.0 \pm 4.6(9 / 60)$ in the cellar population and $31.7 \pm 6.0(19 / 60)$ in the vineyard population. Lower frequencies of inversion-bearing chromosomes were found in the cellar than in the vineyard populations $(t=2.1919$ d.f. $=\infty P<0.05)$. 
Table 3 Observed combinations of inverted and standard arrangements for the three most frequent inverted regions

\begin{tabular}{|c|c|c|c|c|c|c|}
\hline \multirow[b]{2}{*}{$\ln (2 L) t$} & \multirow[b]{2}{*}{$\operatorname{In}(3 L) P$} & \multirow[b]{2}{*}{$\operatorname{In}(3 R) C$} & \multicolumn{2}{|c|}{ Cellar } & \multicolumn{2}{|c|}{ Vineyard } \\
\hline & & & obs. & exp. & obs. & exp. \\
\hline $\ln v$ & Inv & & 5 & 1.9 & 11 & 10.0 \\
\hline Inv & $\mathrm{St}$ & & 19 & 22.1 & 57 & 58.0 \\
\hline St & Inv & & 18 & 21.1 & 33 & 34.0 \\
\hline \multirow[t]{7}{*}{ St } & St & & 249 & 245.9 & 197 & 196.0 \\
\hline & & & \multicolumn{2}{|c|}{$\chi^{2}=4.227^{*}$} & \multicolumn{2}{|c|}{$\chi^{2}=0.032$} \\
\hline & Inv & Inv & 4 & 3.5 & 6 & 8.7 \\
\hline & Inv & St & 20 & 20.5 & 38 & 35.3 \\
\hline & $\mathrm{St}$ & $\operatorname{In} v$ & 38 & 38.5 & 53 & 50.3 \\
\hline & St & St & 229 & 228.5 & 201 & 203.7 \\
\hline & & & \multicolumn{2}{|c|}{$\chi^{2}=0.000$} & \multicolumn{2}{|c|}{$x^{2}=0.821$} \\
\hline $\operatorname{lnv}$ & & Inv & 4 & 3.5 & 21 & 13.5 \\
\hline $\ln v$ & & St & 20 & 20.5 & 47 & 54.5 \\
\hline St & & Inv & 38 & 38.5 & 38 & 45.5 \\
\hline \multirow[t]{2}{*}{ St } & & St & 229 & 228.5 & 192 & 184.5 \\
\hline & & & \multicolumn{2}{|c|}{$\chi^{2}=0.000$} & \multicolumn{2}{|c|}{$\chi^{2}=5.942^{*}$} \\
\hline
\end{tabular}

obs $=$ combinations observed $;$ exp. $=$ combinations expected . ${ }^{*} P<0.05$.

Table $\$$ Observed and expected combinations between inverted (Inv) and non-inverted (St) chromosomal sections of the same chromosome among the F1-larvae

\begin{tabular}{|c|c|c|c|c|c|c|c|}
\hline \multicolumn{2}{|c|}{ Arm } & \multicolumn{3}{|c|}{ Cellar } & \multicolumn{3}{|c|}{ Vineyard } \\
\hline $2 \mathrm{~L}$ & $2 \mathrm{R}$ & obs. & exp. & $\chi^{2}$ & obs. & exp. & $\chi^{2}$ \\
\hline Inv & Inv & 0 & 1.7 & & 8 & 6.5 & \\
\hline Inv & St & 24 & 22.3 & & 61 & 62.5 & \\
\hline St & Inv & 21 & 19.3 & & 20 & 21.5 & \\
\hline St & St & 246 & 247.7 & 1.029 & 209 & 207.5 & 0.229 \\
\hline
\end{tabular}

\begin{tabular}{llrrrrrr} 
& 3R & obs. & exp. & $\chi^{2}$ & obs. & exp. & $\chi^{2}$ \\
\hline Inv & Inv & 6 & 5.2 & & 8 & 12.1 & \\
Inv & St & 18 & 18.8 & & 36 & 32.0 & \\
St & Inv & 57 & 57.8 & & 74 & 69.9 & \\
St & St & 210 & 209.2 & 0.025 & 180 & 184.1 & 1.740
\end{tabular}

obs. $=$ combinations observed; exp. = combinations expected.

As can be seen in Table 5 , the only two inversions detected were $\operatorname{In}(2 L) t$ and $\operatorname{In}(2 R) N S$. Only $\operatorname{In}(2 L) t$ showed a significantly different frequency between the two populations $\{t=2.624$ d.f. $=\infty P<0.01\}$.

The frequencies of each inversion for the same
Table 5 Frequencies, by chromosome arm, of the different gene arrangements of the second chromosome in cellar and vineyard populations

\begin{tabular}{llrrrrr}
\hline \multirow{2}{*}{ Arm } & Arrangements & $\begin{array}{c}\text { Cellar } \\
N=60\end{array}$ & $\begin{array}{l}\text { Freq. Vineyard Freq. } \\
(\%)\end{array}$ & $N=60$ & $\begin{array}{l}\text { Fro } \\
(\%)\end{array}$ \\
\hline $2 \mathrm{~L}$ & 2L(STANDARD) & 54 & 90.0 & 43 & 71.7 \\
& In(2L)t $\quad$ 22D-34A & 6 & 10.0 & 17 & 28.3 \\
\multirow{2}{*}{ 2R } & 2R(STANDARD) & 56 & 93.3 & 53 & 88.3 \\
& In(2R)NS 52A-56F & 4 & 6.7 & 7 & 11.7 \\
\hline
\end{tabular}

$N=$ number of chromosomes analysed.

population were compared between the two parts of the study. There were no differences between the frequencies of the cosmopolitan inversion in the two experiments.

Analysis of relative viabilities. Viability data were collected so as to permit partition of the total variance into (a) the variance between groups of chromosomes tested at the same time (samples); (b) that between chromosomes within these samples; $(c)$ that between replicates within the chromosomes.

Table 6 shows a summary of two-level nested anovas which were carried out for homozygote (excluding lethals) and heterozygote viabilities in both populations. The differences between samples were not significant for either homozygotes or heterozygotes in the two populations. Moreover, significantly greater mean squares were due to chromosomes rather than to replicates in the four groups of analysed data, indicating that there was a real genotypic difference among the chromosomes within populations, these differences being more significant for homozygotes than heterozygotes.

Table 6 Summary of the two-level nested anovas of homozygote and heterozygote viabilities of second chromosome in cellar and vineyard populations

\begin{tabular}{|c|c|c|c|c|c|}
\hline & & Fs, cr & d.f. & Fcr, e & d.f. \\
\hline \multirow{2}{*}{ Cellar } & homozygotes & $0.154 \mathrm{~ns}$ & 3 & $7.629^{* * *}$ & 40 \\
\hline & heterozygotes & $0.006 \mathrm{~ns}$ & 3 & $1.818^{*}$ & 56 \\
\hline \multirow{2}{*}{ Vineyard } & $\int$ homozygotes & $1.929 \mathrm{~ns}$ & 3 & $4.244^{* * * *}$ & 40 \\
\hline & heterozygotes & $0.037 \mathrm{~ns}$ & 3 & $1.847^{*}$ & 56 \\
\hline
\end{tabular}

$F=$ value of $F$ tests; $s=$ samples (groups of chromosomes analysed simultaneously); $\mathrm{cr}==$ chromosomes (within samples); $\mathrm{e}=$ error (replicates within chromosomes); ${ }^{*} P<0.05 ;{ }^{* * *} P<0.001$ 


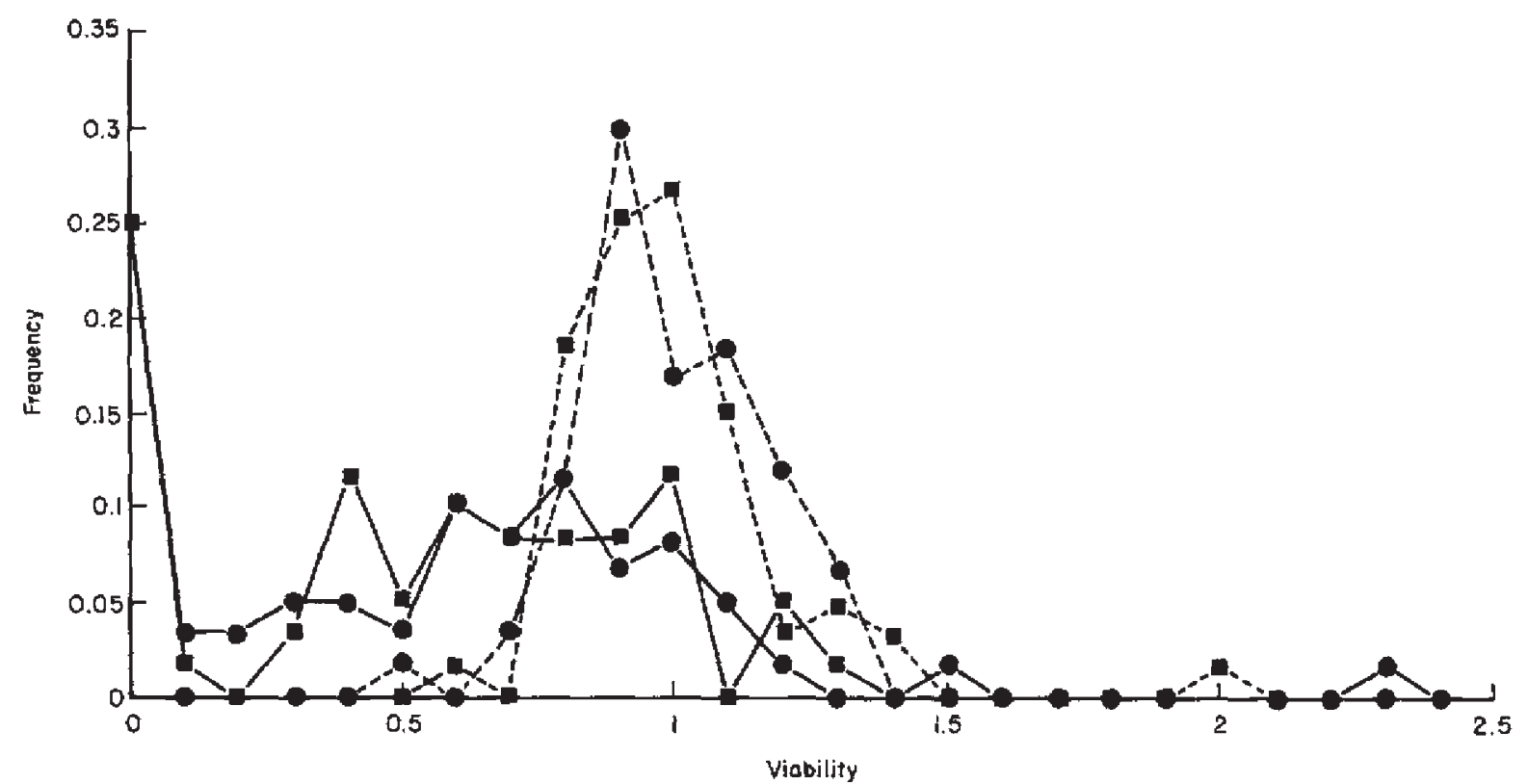

Fig. 2 Frequency distributions of homozygote (_- ) and heterozygote ( - - - ) viabilities of the second chromosomes from cellar ( ) and vineyard (a) populations.

The distributions of homozygote and heterozygote viabilities of the second chromosome can be seen in Fig. 2. The Kolmogorov-Smirnov non-parametric test showed that there were no significant differences between the distributions patterns of the two populations for either homozygote or heterozygote viabilities. The frequency of lethal-carrying chromosomes was the same in the two populations studied $(0.267)$.

The average relative viabilities of homozygotes, homozygotes excluding lethal-carrying chromosomes and heterozygotes are given in Table $7 \mathrm{~A}$. There were no significant differences between the two populations in any of the three measurements. The genetic loads caused by genes affecting viability were estimated using the methods of Greenberg \& Crow (1960) (Table 7B).

The average homozygote viabilities of inversioncarrying chromosomes and inversion-free chromosomes are given in Table 8 . In the vineyard population, there were no significant differences between inversion-free chromosomes and inversion-bearing chromosomes, whether or not lethals were considered. In the cellar, the average viability of inversion-free chromosomes was slightly but not significantly higher than that of inversion-carrying chromosomes, when lethal-carrying chromosomes were excluded.

The average viabilities of heterozygous homokaryotypes (St/St; Inv/Inv) and heterokaryotypes /St/Inv; Inv/Inv $\left.{ }^{\prime}\right)$ of the two populations were also compared. There were no significant differences either in the cellar or in the vineyard populations (Table 9).
Table 7 (A) Average relative viabilities of homozygotes and heterozygotes. (B) Homozygous genetic loads, expressed in lethal equivalents, for the second chromosome in cellar and vineyard populations

(A)

\begin{tabular}{|c|c|c|c|c|}
\hline & \multicolumn{2}{|c|}{ Cellar } & \multicolumn{2}{|c|}{ Vineyard } \\
\hline & $N$ & Average viability & $N$ & Average viability \\
\hline Heterozygotes & 60 & $1.0000 \pm 0.0215$ & 60 & $1.0000 \pm 0.0262$ \\
\hline Homozygotes & 60 & $0.5625 \pm 0.0594$ & 60 & $0.5426 \pm 0.0507$ \\
\hline $\begin{array}{l}\text { Homozygotes } \\
\text { excluding } \\
\text { lethals }\end{array}$ & 44 & $0.7633 \pm 0.0558$ & 44 & $0.7351 \pm 0.0402$ \\
\hline
\end{tabular}

$N=$ number of chromosomes analysed.

(B)

\begin{tabular}{lllll}
\hline Population & Total load & $\mathrm{D}$ & $\mathrm{L}$ & $\mathrm{D} / \mathrm{L}$ \\
\hline Cellar & 0.5754 & 0.2701 & 0.3052 & 0.8847 \\
Vineyard & 0.6113 & 0.3077 & 0.3036 & 1.0135 \\
\hline
\end{tabular}

Load components are: $\mathrm{D}$ for detrimentals and $\mathrm{L}$ for lethals.

As can be seen from Table 10, there was no linkage disequilibrium between lethals and standard-arrangement chromosomes.

Table 11 shows the results on lethal heterozygote 
Table 8 Average homozygote viabilities and their standard error for the second chromosomes with and without inversions. (A) Including lethal-carrying chromosomes; (B) excluding lethal-carrying chromosomes

\begin{tabular}{lll}
\hline (A) & \multicolumn{1}{l}{ Population } \\
\cline { 2 - 3 } & \multicolumn{1}{c}{ Cellar } & Vineyard \\
\cline { 2 - 3 } Chromosomes & $N$ Average viability & $N$ Average viability \\
\hline Inversion-free & $510.5700 \pm 0.0656$ & $410.5323 \pm 0.0635$ \\
Inversion-carrying & $90.5196 \pm 0.1358$ & $190.5649 \pm 0.0823$ \\
\hline
\end{tabular}

(B)

Population

\begin{tabular}{llll}
\cline { 2 - 3 } Chromosomes & \multicolumn{1}{c}{ Cellar } & Vineyard \\
\cline { 2 - 3 } & Average viability & $N$ Average viability \\
\hline Inversion-free & $370.7823 \pm 0.0611$ & $290.7470 \pm 0.0513$ \\
Inversion-carrying & $70.6632 \pm 0.1312$ & $150.7122 \pm 0.0632$
\end{tabular}

$N=$ number of chromosomes.

Table 9 Average heterozygote viabilities for the second chromosome of homokaryotypes ( $\mathbf{S t} / \mathrm{St}$; Inv/Inv) and heterokaryotypes (St/Inv; Inv/Inv') in cellar and vineyard populations

\begin{tabular}{|c|c|c|c|c|}
\hline \multirow[b]{3}{*}{ Genotypes } & \multicolumn{4}{|c|}{ Population } \\
\hline & \multicolumn{2}{|c|}{ Cellar } & \multicolumn{2}{|c|}{ Vineyard } \\
\hline & $N$ & Average viability & $N$ & Average viability \\
\hline $\begin{array}{l}\text { Structural } \\
\text { homozygote }\end{array}$ & 46 & $1.0065 \pm 0.0270$ & 29 & $1.0064 \pm 0.0475$ \\
\hline $\begin{array}{l}\text { Structural } \\
\text { heterozygote }\end{array}$ & 14 & $0.9787 \pm 0.0248$ & 31 & $0.9940 \pm 0.0241$ \\
\hline
\end{tabular}

$N=$ number of genotypes.

relative viability. 'Single-lethal' heterozygote indicates that one of the homologous chromosomes carries at least one recessive lethal gene, and 'double-lethal' heterozygote means that each of the homologous chromosomes carries at least one recessive lethal gene. In the cellar population (Table 11A), single-lethal heterozygotes had a significantly higher viability than lethal-free heterozygotes. The genetic variances in relative viability for lethal-free, single-lethal and for
Table 10 Frequencies of standard arrangements and inversions of lethal-carrying and lethal-free chromosomes in cellar and vineyard populations

\begin{tabular}{lrrrr}
\hline & $\begin{array}{l}\text { Lethal-free } \\
\text { chromosomes }\end{array}$ & \multicolumn{2}{l}{$\begin{array}{l}\text { Lethal-carrying } \\
\text { chromosomes }\end{array}$} \\
\hline Cellar & & & & \\
$\quad$ Standard & 37 & $72.55 \%$ & 14 & $27.45 \%$ \\
$\quad$ Inversion & 7 & $77.78 \%$ & 2 & $22.22 \%$ \\
Vineyard & & & & \\
$\quad$ Standard & 29 & $70.73 \%$ & 12 & $29.27 \%$ \\
$\quad$ Inversion & 15 & $78.95 \%$ & 4 & $21.05 \%$ \\
\hline
\end{tabular}

double-lethal heterozygotes were not significantly different. The average homozygous viabilities of lethalfree chromosomes, which were constituents of lethal heterozygotes and which were constituents of lethalfree heterozygotes, were not significantly different. These results indicate a heterotic effect of the singlelethal heterozygotes and it would imply that the level of recessive lethals in populations ought to be very much higher than the level that we see. In the vineyard population (Table 11B), the double-lethal heterozygotes presented a significant lower viability compared with single-lethal and lethal-free heterozygotes. Table 11 also shows that the effect of the inversions was not found on the lethal heterozygote viabilities.

Allelism rates of lethal chromosomes and effective population size. All lethal chromosomes from both populations were used for calculating the inter- and intrapopulation allelism rates. The number of crosses made within cellar, within vineyard and between cellar and vineyard were 120,120 and 256 , respectively. The respective rates of allelism were 0.0083 ( 1 lethal cross), 0 ( 0 lethal cross) and 0.0039 ( 1 lethal cross) (there are no differences among them).

The effective size of the cellar population $(\mathrm{Ne})$ was estimated by the following formula (Nei, 1968), where the degrees of dominance of lethal genes and the mutation rates to lethals $(u)$ per locus are the same for all loci:

$\hat{N} e=(1-\hat{l g}) / 4(\hat{I g} U-u)$.

Ig stands for the allelism rate of lethal genes and can be estimated by $-\ln \left(1-I c Q^{2}\right) / \ln (1-Q)^{2}$, where $I c$ stands for the allelism rate of lethal chromosomes; $U$ is the total lethal mutation rate; and $Q$ is the frequency of the lethal chromosomes. From the data, $Q=0.2670$, $I c=0.0083$ and $U=0.005$ (c.f. Crow \& Temin, 1964).

Values of $10^{-5}$ and $0.20 \times 10^{-5}$ were used in our calculation for $(u)$; the former estimate comes from the 
Table 11 Average viabilities of lethal-free, single-lethal and double-lethal heterozygotes for cellar population and vineyard populations

\begin{tabular}{|c|c|c|c|c|c|c|}
\hline & \multicolumn{2}{|c|}{ All crosses } & \multicolumn{2}{|c|}{ Inversion-carrying } & \multicolumn{2}{|c|}{ Inversion-free } \\
\hline & $N$ & Average viability & $N$ & Average viability & $N$ & Average viability \\
\hline \multicolumn{7}{|l|}{ Cellar } \\
\hline Non-lethal/non-lethal' & 32 & $0.9500 \pm 0.0243$ & 7 & $0.9557 \pm 0.0247$ & 25 & $0.9484 \pm 0.0304$ \\
\hline Non-lethal/lethal & 24 & $1.0511 \pm 0.0373\}^{*}$ & 9 & $1.0291 \pm 0.0464$ & 15 & $1.0643 \pm 0.0523$ \\
\hline Lethal/lethai' & 4 & $1.0939 \pm 0.0724$ & & & 4 & $1.0939 \pm 0.0724$ \\
\hline \multicolumn{7}{|l|}{ Vineyard } \\
\hline Non-lethal/non-lethal' & 34 & $1.0085 \pm 0.0392$ & 17 & $1.0024 \pm 0.0286$ & 17 & $1.0146 \pm 0.0730$ \\
\hline Non-lethal/lethal & 20 & $1.0148 \pm 0.0386\}$ & 12 & $1.0112 \pm 0.0424$ & 8 & $1,0201 \pm 0.0724$ \\
\hline Lethal//ethal' & 6 & $\left.0.9026 \pm 0.0271\}^{*}\right]$ & 3 & $0.8618 \pm 0.0319\}$ & 3 & $0.9433 \pm 0.0286$ \\
\hline
\end{tabular}

${ }^{*} P<0.05 ;{ }^{* *} P<0.01$.

number of lethal-producing loci per second chromosome $(n=500)$ (c.f. Ives, 1945; Wallace, 1950), and the latter is based on 2400 (Judd et al, 1972).

The estimates of effective size for the cellar population were:

Ne: $u=10^{-5} \rightarrow \approx 12000 ; u=0.2 \times 10^{-5} \rightarrow=8500$.

The effective population size estimated in the cellar indicates that this population is relatively large. In the vineyard, the population size ought also to be large since the lethal allelism rates in the two populations are not significantly different.

\section{Discussion}

The data regarding the total frequency of inversionbearing chromosomes indicate a lower frequency in the cellar than in the vineyard population. With respect to this difference, we will discuss some possibilities that could explain it.

The first possibility is that the factors associated with the cellar habitat can create different adaptive responses in Drosophila melanogaster to those produced by the vineyard habitat, and that the inversions seem to be involved in some way in these responses.

The conditions in the cellar and the vineyard are substantially different. The presence of alcohol (principally ethanol) at high concentrations is one of the characteristics of the cellar. McKenzie \& Parsons (1972) found that cellar flies were more resistant to alcohol than flies from vineyards.

However, alcohol is not the only characteristic com- ponent of wine and there are related products present. in the cellars that can be used as food by the flies (Monclús \& Prevosti, 1978-1979). Stalker (1976, 1980 ) found an association, in Drosophila melanogaster, between different ecological niches (i.e. different food resources) and inversion frequencies.

Inoue et al. (1984) suggested that a possible cause of the lower frequency of inversions in the west of mainland Japan was environmental pollution by insecticides and the emergence of resistant flies in the population. For a fly to become resistant, recombination is an important genetic process since it has to accumulate many resistant genes along the chromosome. Inversion chromosomes prevent recombination by the action of crossover suppression. Therefore, if the population adapts to the polluted environment, it may become resistant to insecticides at the cost of polymorphic inversions in the wild. A similar reasoning could be applied to the cellar population since some unfavourable product for Drosophila could be present at this habitat. Flies in the cellar might be adapting to this new environment. If the adaptive changes involved substitutions at many loci, the organisms would have to be capable of bringing the mutations required into the appropriate linkage phase and this would be difficult or impossible in chromosomes bearing inversions. Therefore these chromosomes would have a reduced inversion frequency in the evolved population.

Although other specific factors from the cellax habitat could be related with the different frequencies of inversions between the two populations, we think that all the cellar factors, as a whole, are probably the cause of this difference. 
A second possibility which should be discussed is that the different frequencies of inversions in the two populations could be related to the environmental changes, mostly temperature, that occur in the natural populations throughout the year. Stalker $\{1980\rangle$ and Knibb (1982) observed seasonal changes in inversion frequencies in natural populations. The frequency of standard arrangements was significantly reduced by selection during the warm part of the year and restored again the following winter. Inoue et al (1984) suggested that perhaps the higher frequency of inversions in southern populations may result from some indirect responses of inversions to the higher temperature.

The temperature changes are stronger in the vineyard than in the cellar habitat. The captures in the cellar were carried out in spring for both parts of the study. For the vineyard, the captures were made in summer for the first part and in winter for the second. No differences were detected in the total frequencies of inversions in these two parts from the vineyard. Taking into account that this habitat is more susceptible to environmental shifts, since it is an open habitat, and no changes in the inversion frequencies occur, it is clear that the differences detected between the cellar and vineyard populations cannot be due to seasonal changes. Moreover, in a similar study, González \& Ménsua (1987b) also observed significant differences in the inversion frequencies, between cellar and vineyard, despite the captures of both populations having been made in the same season of the year.

A third possibility is that the differences in the inversion frequencies are due to an effect of genetic drift. Although both second and third chromosome inversion frequencies change in the same direction, this does not imply necessarily than the population differentiation cannot be chance.

With respect to the fitness component studied in the present work, no differences seem to exist between the cellar and the vineyard populations. As well as the frequencies of lethal-carrying chromosomes being the same in the two populations, there were no significant differences between the distribution patterns of the two populations for homozygote or for heterozygote viabilities.

In the two populations studied, neither the homozygote nor the heterozygote viabilities differ between inversion-carrying chromosomes and inversion-free chromosomes. These results are different to those found by González \& Ménsua (1987a) in a study of two similar habitats. They found in the cellar population that the inversion-free chromosomes had greater average homozygote viability than those with inversions, whereas the heterozygote viabilities were similar for both chromosome types. The behaviour of the chromosomes in the cellar analysed by González and Ménsua was analogous to that of the chromosomes in cage populations studied by other authors (Inoue, 1979; Watanabe et al. 1976).

Our data on allelism rates of lethals and population sizes agree with the data contributed by González \& Ménsua (1987a) for two populations from similar habitats. The population sizes estimated in both studies are relatively large. We support the suggestion of these authors that the cellar and vineyard populations are subpopulations of a large population.

\section{References}

BRIDOES, C. B. 1935. Salivary chromosome maps with a key to the banding of the chromosomes of Drosophila melanogaster. 3. Heredity, 26, 60-64.

CROW, F. J. AND TEMIN, R. G. 1964. Evidence for partial dominance of recessive lethal genes in natural populations of Drosophila. Am. Naturalist, 98, 21-23.

GONZÁLEZ, A. AND MÉNSUA, J. L. 1987a. Genetic polymorphism and high detrimental load in natural populations of Drosophila melanogaster from cellar and vineyard. Heredity, 59, 227-236.

GONZALEZ, A. AND MÉNSUA, J. L. 1987b. Low frequency of inversion-carying chromosomes in a population of Drosophila melanogaster from a cellar habit. Génét. Sél. Evol, 19, 297-306.

GREENBERG, R. AND CROW, J. F. 1960. A comparison of the effect of lethal and detrimental chromosomes from Drosophila populations. Genetics, 45, 1154-1168.

HALDANE, J. B. S. 1956 . Estimation of viabilities. J. Genetics, 54, 294-296.

INOUE, Y. 1979. The fate of polymorphic inversions of Drosophila melanogaster transferred to laboratory conditions. Japan, J. Genetics, 54, 83-96.

INOUE, Y. AND WATANABE, T. K. 1979. Inversion polymorphisms in Japanese populations of Drosophila melanogaster. Japan. J. Genetics, 54, 69-82.

INOUE, Y., WATANABE, T. AND WATANABE, T. R. 1984. Evolutionary change of the chromosomal polymorphism in Drosophila melanogaster populations. Evolution, 38, 753-765.

IVES, P. T. 1945. The genetic structure of American populations of Drosophila melanogaster. Genetics, 30, 167-196.

JUDD, B. H., SHEN, M. W. AND KAUFMAN, T. C. 1972. The anatomy and function of a segment of the $\mathrm{X}$ chromosome of Drosophila melanogaster. Genetics, 71, 139-156.

KNTBB, w. R., OAKESHOTT, J. G. AND GIBSON, J. B. 1981. Chromosome inversion polymorphisms in Drosophila melanogaster. I. Latitudinal clines and associations between inversions in Australasiar populations. Genetics, 98, 833-847.

KNIBB, w. R. 1982. Chromosome inversion polymorphisms in Drosophila melanogaster. II. Geographic clines and climatic associations in Australasia, North America and Asià. Genetica, 58, 213-221.

LINDSLEY, D. L. AND GRELL, E. H. 1972. Genetic variations of 
Drosophila melanogaster: Carnegie Inst. Wash. Publ. No. 627.

MCKenZIE, J. A. AND PARSONs, P. A. 1972. Alcohol tolerance. An ecological parameter in the relative success of Drosophila melanogaster and Drosophila simulans, Oecologia, 10 , 373-388.

ME'TLER, L. E., VOELKER, R. A. AND MUKAI, T. 1977. Inversion clines in populations of Drosophila melanogaster. Genetics, 87, 169-176.

MONClUS, M. AND PREYostı, A. 1978-1979. Cellar habitat and Drosophila populations. Genética Ibérica, 30-31, 189-201.

MUKAI, T. AND YAMAGUCHI, o. 1974. The genetic structure of natural populations of Drosophila melanogaster. XI. Genetic variability in a local population. Genetics, 76, 339-366.

NEl, $M .1968$. The frequency distribution of lethal chromosomes in finite populations. Proc. Nat. Acad. Sci. (USA), $60,517-524$.
RIM, N. R., LEE, B. S. AND LEE, T. H. 1986. Chromosomal inversion studies in local populations of Drosophila melanogaster. Korean J. Genetics, 8, 12-22.

STALKER, H. D. 1976. Chromosome studies in wild populations of Drosophila melanogaster. Genetics, 82, 323-347.

STALKER, H. D. 1980. Chromosome studies in wild populations of Drosophila melanogaster. II. Relationship of inversion frequencies to latitude, season, wing-loading and flight activity. Genetics, 95, 211-223.

WALLACE, B. 1950. Allelism of second chromosome lethals in Drosophila melanogaster. Proc. Nat. Acad. Sci. (USA), 36, 654-657.

WATANABE, T. K., YAMAGUCHI, O. AND MUKAl, T. 1976. The genetic variability of third chromosomes in a local population of Drosophila melanogaster. Genetics, 82, 63-82.

ZACHAROPOUlou, A. AND PELECANOS, M. 1980. Seasonal and year to year inversion polymorphism in a Southem Greek Drosophila melanogaster population. Genetica, 54, 105-111. 